\title{
Changes in publication statistics when electronic submission was introduced in an international applied science journal
}

\author{
Howard J. Swatland
}

\begin{abstract}
In a refereed journal in the food and agriculture sector, papers were tracked over a five-year period during the introduction of electronic submissions. Papers originated in the Americas and Pacific region and were processed in Canada. Acceptance times for revised papers were reduced $(P<0.001)$ to $59 \%$ of the original, from $156.5 \pm 69.1$ days to $92.8 \pm 57.5$ days. But the start of electronic submission coincided with a change in the geographical origin of papers, with papers from Anglophone countries changing from a $61 \%$ majority to a $42 \%$ minority. It is possible that submissions from non-Anglophone sources were facilitated, thus creating challenges to the traditional Anglophone reviewer population.
\end{abstract}

\section{Introduction}

Meat is either the primary or terminal product of global animal industries. As a major source of protein in the human diet and a major trading commodity, meat has an international strategic importance comparable with oil or wheat. A scientific and technological basis for the meat industry developed with government funding. One of the earliest laboratories was the Low Temperature Research Station (LTRS) in Cambridge, England, founded in 1922. Specialized scientific papers on meat science soon appeared, but were mostly published in British government journals (such as Report of the Food Investigation Board). By the 1940s, papers from LTRS and a growing number of meat research laboratories in other countries began to appear as refereed papers in journals of general agriculture, or in food and animal science journals. Then, in 1977, the late Professor Ralston Lawrie of the University of Nottingham (at LTRS until 1964) founded a specialized journal - Meat Science. ${ }^{1}$

Electronic submission and reviewing of papers for Meat Science started in January 2006, rather late relative to many comparable journals because the Elsevier Editorial System (EES) required modification to serve two associate editors working under a chief editor. The data reported here were collected by the author while an associate editor based in Canada and responsible for the Americas and Pacific region. Meat Science has a mandate to be an international journal, but it is also the official journal of the American Meat Science Association.

The importance of the peer review system is widely recognized. ${ }^{2}$ It affects many aspects of meat science, from the allocation of grant funding for research, through to promotion, tenure and awards for individual meat scientists. Peer review is virtually the only system for maintaining the quality of meat science papers, a few of which have major effects on industrial practices and government regulations. But peer reviewing is a system under pressure, with many inherent conflicts ${ }^{3}$ and with many potential reviewers unable to contribute their time because they are too busy writing their own research papers or teaching or administering. It is difficult to predict where electronic publishing will take us ${ }^{4}$ and, hence, important to document its initial impact.

Electronic communication is almost instantaneous while delays of weeks often occur internationally with traditional mail. Thus, electronic publishing is obviously faster than conventional publishing. But how much faster? Are papers reviewed and accepted in $20 \%$ or $80 \%$ of the original time? At the present time, we have a generation of editors who witnessed the change. Failure to record the change will leave future generations guessing. And how else might electronic communication affect science publishing? The study reported here was unfunded and prompted by curiosity. Hopefully, readers interested in science communication will find the details interesting. 


\section{Methods}

Data from late 2002 to the end of 2005 (before EES) were compared using simple statistics ${ }^{5}$ with data from 2006 and 2007 (using EES). Before EES, $n=441$ papers and 695 reviews. Using EES, $n=385$ papers and 424 reviews

Data were obtained from software written initially to produce form letters and envelope labels and to select reviewers. For each paper submitted, a file of 100 lines was used to store communication details and to record the dates of letters sent and received, and of actions taken. It was not uncommon for a request to review a paper to be declined or ignored many times by many different individuals, and it was not practical to store the names of all these refractory individuals. Hence, data are limited to the time lapse between first receiving a paper (at which time all papers were first sent to reviewers) and the latest request to a reviewer, who may or may not have responded. Each data file had space for two reviewers plus an arbitrator when two reviewers disagreed. There were unavoidable sources of error in the recording system, foremost that everything was timed from the receipt or sending of communications. For example, manuscripts sent from a remote geographical region by surface mail were timed from their receipt by an active editor. Thus, we cannot distinguish between a slow mail delivery and an editor on vacation. However, vacation times and patterns were similar for the years examined.

\section{Results}

\section{Reviewing and processing times}

Using EES, the average time for a review decreased $(P<0.001)$ from $52.9 \pm 31.1$ days to $30.0 \pm 22.1$ days. For unsatisfactory papers, this decreased $(P<0.001)$ the rejection time from $77.7 \pm 39.6$ days to $36.5 \pm 28.3$ days. For papers requiring revisions before acceptance, the revision time was reduced $(P<$ $0.001)$ from $72.0 \pm 57.1$ days to $38.6 \pm 40.0$ days. Acceptance times for revised papers were reduced $(P<$ 0.001 ) from $156.5 \pm 69.1$ days to $92.8 \pm 57.5$ days.

The overall decision reached by reviewers changed. Before EES, $48.6 \%$ of papers were accepted and sent to the printer. Using EES, only $34.0 \%$ were judged acceptable.

No effects associated with postal distance were detectable. For example, reviews from the USA took 50.93 \pm 30.75 days to reach Canada while those from South America and the Pacific region took $53.95 \pm 31.2$ days $(P>0.05)$. Thus, distance-related effects were small and unimportant both before and using EES.

\section{Geographical origins of papers}

The start of using EES coincided with a change in the geographical origin of papers, as detailed in Table 1. Before EES, the dominant source was Anglophone countries (61\%). Using EES, only 42\% of papers originated from Anglophone countries. This change in percentage was not entirely caused by increased numbers of papers from non-Anglophone countries. Submissions from Anglophone countries decreased from 90 papers in 2003 to 69 papers in 2007. Looking at monthly submission numbers for the whole period from September 2002 to January 2008, the increase in the rate of total submissions $(r=0.45, P<$ $0.001)$ was entirely due to an increase in non-Anglophone submissions $(r=0.64, \mathrm{P}<0.001)$. Anglophone submissions may have declined slightly $(\mathrm{r}=-0.03, \mathrm{P}>0.05)$.

\section{Difficulty of obtaining reviews}

Before EES, $14.0 \%$ of papers were accepted with only a single review. Using EES, $7.3 \%$ of papers were accepted with only a single review. Before EES, $12.2 \%$ of papers were rejected with only a single review. Using EES, $6.1 \%$ of papers were rejected with only a single review.

Examining the combined data on individual reviewers before and using EES, only $50.7 \%$ had a perfect record of never declining or ignoring an invitation and of always submitting their reviews within a reasonable period of time. Examining the data on invitations both before and using EES, only 39.4\% 


\begin{tabular}{|l|l|l|l|l|}
\hline Country & Before EES & \% & Using EES & \% \\
\hline Argentina & 10 & 2.3 & 7 & 1.82 \\
\hline Australia & 33 & 7.5 & 15 & 3.9 \\
\hline Brazil & 35 & 7.9 & 31 & 8.0 \\
\hline Canada & 31 & 7.0 & 12 & 3.1 \\
\hline Chile & 3 & 0.7 & 3 & 0.8 \\
\hline China & 23 & 5.2 & 70 & 18.2 \\
\hline Japan & 39 & 8.8 & 30 & 7.8 \\
\hline Korea & 28 & 6.3 & 46 & 11.9 \\
\hline Malaysia & 1 & 0.2 & 0 & 0 \\
\hline Mexico & 9 & 2.0 & 6 & 1.56 \\
\hline New Zealand & 30 & 6.8 & 15 & 3.9 \\
\hline Taiwan & 15 & 3.4 & 12 & 3.1 \\
\hline Thailand & 3 & 0.7 & 6 & 1.6 \\
\hline Uruguay & 1 & 0.2 & 3 & 0.8 \\
\hline U.S.A. & 174 & 39.5 & 118 & 30.6 \\
\hline Venezuela & 3 & 0.7 & 4 & 1.0 \\
\hline
\end{tabular}

Table 1. Geographical origin of papers.

resulted in a review being obtained within a reasonable period of time. As explained earlier, for these indices, it was not possible to compare data obtained before, and using EES. However, when using EES, of those who accepted an invitation to review a paper, only $91.2 \%$ sent in a review.

\section{Discussion}

\section{Reviewing and processing times}

Postal communication is necessarily slow, especially with security issues for parcels at international borders. Even in sturdy envelopes, manuscripts and figures may be damaged in transit. There are many inexplicable mail losses in some countries. It would be wrong, however, to assume that email is completely superior to the postal system. The most common cause of failure is that the intended recipient has changed their email address. Spam filters, full mail-boxes and inoperative servers also contribute to the problems. One might suspect that prospective reviewers capable of putting an envelope in a waste bin are equally capable of hitting a delete button. Thus, critical questions remain unanswered. Electronic submission reduces mail times, but does it change the quality of reviewing or the length of time taken to review a paper? The quality of reviewing is difficult to evaluate, and previous studies have produced some surprises - such as members of editorial boards writing lower quality reviews than young researchers. $^{6}$

\section{Geographical origins of papers}

Changes in the geographical origin of papers were difficult to test statistically. Are the changes shown in Table 1 evidence of a global shift in international meat research? Much of the conventional research in meat science requires a pilot plant with abattoir and meat processing facilities. Recent advances in meat hygiene make these prohibitively expensive to operate and there are examples of complete meat research institutes being closed (for example, LTRS became the Meat Research Institute which closed in 1990). But one of the fastest growing sectors is the market for processed meat products in Asian countries, which is supported by low-cost research within food science departments. Thus, electronic submission has enhanced communication with countries such as China, where previous communication was minimal and where meat research is now rapidly developing.

These changes in the geographical origins of papers have created problems. Acceptable papers in an Anglophone journal require two things - acceptable science and acceptable English. The latter can only 
be judged by Anglophone reviewers. Thus, an increase in papers from non-Anglophone countries increases the load for already recalcitrant Anglophone reviewers. If a journal has an acceptance rate of $50 \%$, for example, and each paper should have two reviews, then each corresponding author must review four papers from other corresponding authors if the peer group of authors and reviewers is to be self sufficient. If less than half the corresponding authors are Anglophones capable of evaluating the English language, then each Anglophone author must review 8 papers. In response to this problem, the Americas and Pacific region for Meat Science was divided, and now has an associate editor in the USA for the Americas, and an associate editor in China for the Pacific region. In addition, three technical editors were added to the on-line system for editors.

\section{Difficulty of obtaining reviews}

In an ideal world, the fate of a paper would be decided by two fully qualified, independent and conscientious reviewers who would both reach the same conclusion. In the real world, it is very difficult to be fully qualified in an interdisciplinary subject such as meat science which ranges from biophysics to genomics, and from statistical testing of sensory responses to abattoir technology. In a world where we must all be educated at one school or another, and where personal communications and conferences are useful assets, it is doubtful whether anyone is completely free to make a completely independent judgment on a scientific research paper. Time and other responsibilities are the enemies of those who would be conscientious. Thus, we see the fate of a minority of papers being decided by a single review. At first sight this may seem very undesirable, but what if the single review is qualified, independent and conscientious? Would this be less reliable than two reviews - both unqualified, biased and careless? Thus, if the value of a single review may be greater than that of two reviews, we must be careful of reviewer statistics. It might appear from the results that the start of EES coincided with a reduction in the number of papers decided by a single review. But this does not take into account the pressures of reduced processing times required the editor to review papers in detail, increasing from $7.8 \%$ of papers before EES to $15.2 \%$ of papers using EES. The value of an editor reviewing the quality of the reviews themselves is widely appreciated and supported by quantitative data.

\section{Future developments}

It is not yet possible to predict the future of publishing in the agricultural sciences. A myriad of new possibilities is now feasible. Our historical model of a journal article on a printed paper page being approved and improved by two anonymous reviewers is changing, or about to disappear. With traditional publishing, the dominant problem was that we had far more prospective authors than willing reviewers. Typically, it is the poor manuscripts that nobody wants to review. ${ }^{8}$ With electronic publishing, the problem is even more serious because of the erosion of our Anglophone reviewer base. If meat scientists cannot solve this problem, then the reliability of our peer review system will be compromised.

If we wish to keep publishing with English as our common language of communication, then clearly we need to help non-Anglophone authors with their English. When papers are reviewed, we need to separate judging the science from judging the English - otherwise we cannot ask our successful non-Anglophone authors to review papers. Computer-based translation, especially of the simple English used in scientific papers, could be of great value in science publishing.

We are also witnessing changes in the business models of science publishing. A common early model was for members of a scientific society to elect an editor and reviewers for a fixed term. Authors paid to have their papers printed. The editor and reviewers were senior members of the scientific society, and the quality of their judgments was readily apparent to members of the society. Commercial publishers have changed the model, transferring the costs of publication from authors to buyers of the journal and often selling individual papers electronically. What they have lost is the cooperative, volunteer spirit of society members acting as reviewers. What we urgently need for commercial journals is a new business model containing incentives for reviewers. Funding agencies and promotion and tenure committees in university and government institutions might help by starting to count papers reviewed - not just papers published. 


\section{Notes and references}

${ }^{1}$ D. Ledward (2007), Ralston Andrew Lawrie (1924-2007): an appreciation, Meat Science 77(4) 709.

${ }^{2}$ Wikipedia, The Free Encyclopedia, Peer review, Wikipedia contributors,

http://en.wikipedia.org/w/index.php?title=Peer_review\&oldid=186144916, accessed on January 22, 2008.

${ }^{3}$ M. Hewings (2004), An 'important contribution' or 'tiresome reading'? A study of evaluation in peer reviews of journal article submissions, Journal of Applied Linguistics 1(3) 247.

${ }^{4}$ L.A. Davidson (2005), The end of print: digitization and its consequence - revolutionary changes in scholarly and social communication and in scientific research, International Journal of Toxicology 24(1) 25.

${ }^{5}$ R.G.D. Steel and J.H. Torrie, Principles and procedures of statistics. A biometrical approach, McGraw-Hill Book Company, New York (1980).

${ }^{6}$ N. Black et al. (1998), What makes a good reviewer and a good review for a general medical journal?, Journal of the American Medical Association 280(3) 280.

${ }^{7}$ M.L. Callaham et al. (1998), Reliability of editors' subjective quality ratings of peer reviews of manuscripts, Journal of the American Medical Association 280(3) 229.

${ }^{8}$ T. Stamm et al. (2007), A retrospective analysis of submissions, acceptance rate, open peer review operations, and prepublication bias of the multidisciplinary open access journal Head and Face Medicine, Head and Face Medicine 3 27. Epub: 2007 Jun 11.

\section{Author}

Howard Swatland started research at LTRS in 1967 and is now Professor Emeritus at the University of Guelph. He has published 221 refereed papers, 6 textbooks and 11 chapters in other books. His main research areas are histochemistry and the development of fibre-optic sensors.

E-mail: swatland@uoguelph.ca.

How TO CITE: H.J. Swatland, Changes in publication statistics when electronic submission was introduced in an international applied science journal, Jcom 07(04) (2008) A03. 